DOI: 10.4274/gulhane.galenos.2020.1124

Gulhane Med J 2020;62:281-3

\title{
A rare cause of acute abdomen; paratubal cyst torsion
}

\author{
(1) Zafer Şenol, (1) Taygun Gülşen \\ Istanbul Sultan 2. Abdulhamid Han Training and Research Hospital, Clinic of General Surgery, Istanbul, Turkey
}

\section{Date submitted:}

29.04.2020

Date accepted:

11.05.2020

Online publication date:

15.12.2020

\section{Corresponding Author:}

Zafer Şenol MD, Istanbul Sultan

2. Abdulhamid Han Training and

Research Hospital, Clinic of General

Surgery, Istanbul, Turkey

zafersenol@yahoo.com

ORCID:

orcid.org/0000-0002-6865-3716

Keywords: Paratubal cyst, acute abdomen, torsion

\begin{abstract}
Paratubal cysts are asymptomatic embryological residues. These cysts are mostly diagnosed in the adolescent and reproductive period. Generally, its dimensions are small, but complications such as rupture, torsion, or hemorrhage may develop. Paratubal cysts are mostly found by chance on ultrasound examination. In this case, we present our 43-year-old patient, who presented with abdominal pain and abdominal distention. In the tomographic examination, it was observed that there was a giant mass in the abdomen, and it was evaluated in our examinations that our patient was anemic. During laparotomy, paratubal cyst was diagnosed and therefore cystectomy and left salpingectomy were performed.
\end{abstract}

\section{Introduction}

Paratubal cysts constitute $10-20 \%$ of all adnexial masses and they exist in the broad cord between the ovary and tube. They arise from mesonephric, mesotelial or mesonephric remnants. Even if paratubal cysts have been reported in all female age groups, they are seen mostly in between 20 and 40-year-old women. These cysts have thin walls. Preoperative differential diagnose is very difficult due to the closeness to the ovary. Paratubal cysts are usually small and asymptomatic. However, bigger lesions can reach a size of $20 \mathrm{~cm}$ or more and become symptomatic with complications such as torsion, hemorrhage, perforation and neoplasm (1). Most of these cysts are benign; on the other hand, borderline tumors and carcinomas have been reported as well. Smaller lesions can be followed. Bigger lesions, symptomatic lesions and sonographic uncertain findings (septations, papillations, liquid and solid components) are usually investigated surgically. Classic treatment is the enucleation of the cyst from the mesosalpynx without damaging the ovaries and fallopian tubes (2). However, salpyngooopherectomy can rarely be needed in complicated cases $(3,4)$. In this article, we present the management of a patient who had an abnormally large paratubal cyst.

\section{Presentation of Case}

Our patient was a 43-year-old female, having 3 gravidities and 3 parities. The main complaint of our patient was abdominal pain which had been lasting for two months. During physical examination, the abdomen was distended and there were general palpational sensitivities.

In the abdominal tomography, a $28 \times 22 \mathrm{~cm}$ mass was detected and evaluated as mesenteric cyst, which reached from the epigastric area to the pelvis in abdominal midline superior, to abdominal wall in anterior, to prevertebral area in posterior, to the intestines in lateral areas. And free fluid was seen together with the cyst in inferior. The physical examination and ultrasonographic scan were performed as a result of the consultation of obstetrics and gynecology and no gynecological pathology was evaluated. The patient was evaluated as anemic 
in the tests (hemoglobin: $7.74 \mathrm{~g} / \mathrm{dL}$, hematocrit: $24.63 \%$ ). All the other tests including tumor markers were seen in normal limits.

During explorative laparotomy, a purple, about $25-30 \mathrm{~cm}$ mass was seen as soon as the abdomen was entered. The mass was seen as left ovarian originated and tortioned. It was detortioned. Then, it was excised with the ovary by fixing its root. Free fluid was seen inside the abdomen and a sample was taken for pathological study. Then, it was aspirated. Inside of the abdomen was washed abundantly with saline. The right ovary and uterus were evaluated as normal. Then a Jacksonpratt drainage was placed in the Douglas cavity. The operation was finished by closing the layers anatomically (Figures 1, 2).

The patient was discharged after pulling the drainage out on the postoperative $5^{\text {th }}$ day. In the pathological study, serohemorrhagic fluid discharge from the cystectomy material was seen. The wall of the cyst was seen as hemorrhagic and brown purple colored. Macrophages full of hemosiderin were seen on the wall of the cyst. When the abdominal fluid was studied pathologically, it was seen as malignancy-negative.

\section{Discussion}

Paratubal cyst is a vesicle which is full of liquid and unilaterally growing on the broad ligament between the uterus and ovary. The origin of these tumors can be referred to the ovaries because tubes cannot usually be seen in ultrasonographic examination.

Characteristic ultrasonographic findings such as nonstromal, unilateral cystic mass can help the differential diagnosis of paratubal cyst. Paratubal cysts are assumed that they are originated from the remnants of paramesonephric (mullerian)

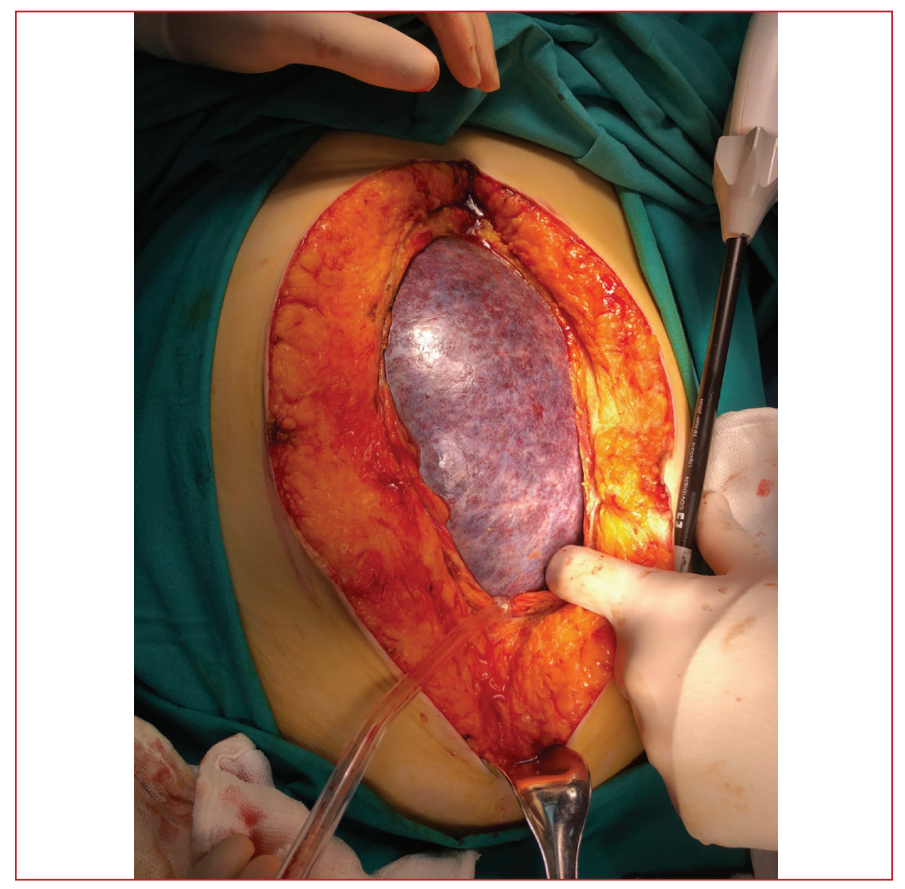

Figure 1. The mass rests against the anterior abdominal wall and mesonephric (wolffian) ducts which exist during urogenital embryologic development.

Paratubal cysts constitute $10 \%$ of whole adnexial masses (5). They are not rare, but they are found incidentally because they are usually asymptomatic. Therefore, the real incidence of them is actually unknown. When paratubal cysts are symptomatic, they often appear with unilateral pelvic pain. Symptoms start to appear when the cyst grows extremely, bleeds, and becomes tortioned or ruptured. In our case, the cyst was extremely growing with tortion and hemorrhage.

Paratubal cysts are usually bound to mesosalpynx with a peduncle and tortion can occur around this $(6,7)$. The incidence of paratubal cyst is uncertain but it must be suspected in the patients with acute or intermittent pelvic pain. In most cases, the diagnosis of tortion can be made with only surgical exploration. Malignant neoplasms can sometimes develop in paratubal cysts (8).

The size of paratubal cysts can change between 2 and 20 $\mathrm{cm}$ but most of the cases are between 6 and $10 \mathrm{~cm}$ (9). Bigger paratubal cysts were reported in the literature $(10,11)$. The size of the cyst was measured as $30 \mathrm{~cm}$ and weighted at $4.5 \mathrm{~kg}$ in our case.

Treatment options for paratubal cysts can be selected according to the patient's age, parity, existing gynecologic pathologies and neoplastic degeneration. There is no need to intervene or constantly observe for paratubal cysts which have a radius of $<10 \mathrm{~cm}$ and are seen simple in ultrasound. Surgical treatment of paratubal cyst is simple excision. Giant paratubal cysts are extraordinary masses and they must be treated with laparotomy. Laparoscopic approach is also reliable, but the size of the cyst is a limiting factor.

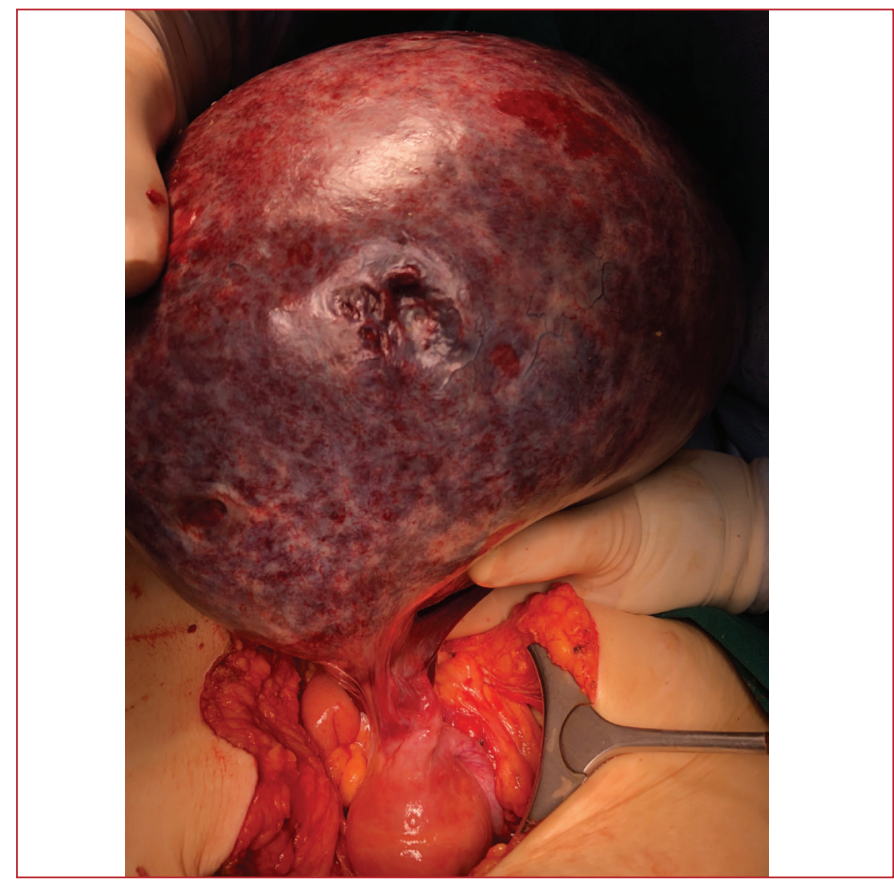

Figure 2. View after mass detortion 


\section{Conclusion}

Consequently, if there is not any ultrasonographic malignancy criteria in giant cystic masses, paratubal cyst must be considered in differential diagnosis. Cyst excision protecting the ovary is enough in cases without any complications. Salpyngooopherectomy must be performed as well in the tortion cases with circulation disorder and suspicion of malignancy.

\section{Ethics}

Informed Consent: Written informed consent was obtained from the patient.

Peer-review: Externally peer-reviewed.

\section{Authorship Contributions}

Surgical and Medical Practices: Z.Ş., T.G., Concept: Z.Ş., T.G., Design: Z.Ş., T.G., Data Collection or Processing: Z.Ş., T.G., Analysis or Interpretation: Z.Ş., T.G., Literature Search: Z.Ş., T.G., Writing: Z.Ş., T.G.

Conflict of Interest: No conflict of interest was declared by the authors.

Financial Disclosure: The authors declared that this study received no financial support.

\section{References}

1. Perlman S, Hertweck P, Fallat ME. Paratubal and tubal abnormalities. Semin Pediatr Surg. 2005;14:124-134.

2. Koc E, Turkyilmaz C, Atalay $\mathrm{Y}$, Basaklar C, Bideci A. Neonatal ovarian cyst as-sociated within testinal obstruction. Indian J Pediatr. 1997;64:555-557.
3. Breech LL, Hillard PJ. Adnexal torsion in pediatric and adolescent girls. Curr Opin Obstet Gynecol. 2005;17:483494.

4. Savic D, Stankovic ZB, Djukic M, Mikovic Z, Djuricic S. Torsion of malignant ovarian tumors in childhood and adolescence. J Pediatr Endocrinol Metab. 2008;21:10731078.

5. Darwish AM, Amin AF, Mohammad SA. Laparoscopic management of paratubal and paraovarian cysts. JSLS. 2003;7:101-106.

6. Muolokwu E, Sanchez J, Bercaw JL, et al. The incidence and surgical management of paratubal cysts in a pediatric and adolescent population. J Pediatr Surg. 2011;46:21612163.

7. Kiseli M, Caglar GS, Cengiz SD, Karadag D, Yılmaz MB. Clinical diagnosis and complications of paratubal cysts: review of the literature and report of uncommon presentations. Arch Gynecol Obstet. 2012;285:1563-1569.

8. Samaha M, Woodruff JD. Paratubal cysts: frequency, histogenesis, and associated clinical features. Obstet Gynecol. 1985;65:691-694.

9. Smorgick N, Herman A, Schneider D, Halperin R, Pansky M. Paraovarian cysts of neoplastic origin are underreported. JSLS. 2009;13:22-26.

10. Varras M, Akrivis Ch, Polyzos D, Frakala S, Samara Ch. A voluminous twisted paraovarian cyst in a 74-year old patient: case report and review of the literature. Clin Exp Obstet Gynecol. 2003;30:253-256.

11. Idotta R. Removal of a voluminous serous papillary paraovarian cystadenoma by endoscpic surgery. A case report. Clin Exp Obstet Gynecol. 2000;27:150-151. 